- Options for Change is a landmark document developed with an unusually broad professional input; some still seem unaware of its scope.

- Key issues include local commissioning, remuneration, prevention, patient involvement, high quality appropriate care, the team and IT .

- As NHS legislation evolves, Options is likely to have an important role in the development of NHS dentistry.

- Options will impact on the working lives of many GDPs as, under current proposals in England, local contracting will be based on this framework.

- The vision for the future of NHS dentistry under Options is quite radical. It sets out a blueprint, delivered via Primary Care Trusts, which will be shaped by the needs of patients in the 21st century for high quality dental services which are responsive to local needs and allow the dental team to focus on preventive measures to combat dental disease and health inequalities.

- Options proposes that this new framework should be tested and evaluated in demonstration (field) sites.

- Reports from three task groups make important recommendations on service delivery, education, training and the dental team.

\title{
NHS Dentistry: Options for Change in context - a personal overview of a landmark document and what it could mean for the future of dental services
}

\author{
N. B. Pitts ${ }^{1}$
}

NHS Dentistry: Options for Change, ${ }^{1}$ published in August 2002, is clearly a landmark document in terms of the breadth and scope of the agenda set out in its 62 pages. However, in spite of wide coverage and publicity, it seems that there are apparently still many who have yet to appreciate that the range of its contents is so comprehensive, or that this document was developed with an unusually broad professional input.

Options for Change set out a possible framework for the way forward, making clear that this was an agreed direction of travel and that the detail needed to be worked-up jointly and trialed. This framework and the contents of the Options document are likely to have an important role in the future development of NHS dental services and are therefore likely to impact on the working lives of many GDPs and others in primary care dentistry. Under current proposals going through Parliament in England, it is likely that local contracting for dental services will be based on many of the principles set out in the document.

Options for Change has been described as perhaps the most radical and ground breaking opportunity for NHS dentistry to finally move forward after prolonged periods of stagnation and disharmony. The Options agenda has the potential to bring in a new style of NHS practice for dentistry,

${ }^{1}$ Professor of Dental Health and Director of Dental Health Services Research Unit, University of Dundee.

Correspondence to: DHSRU, The Mackenzie Building, Kirsty Semple Way, Dundee DD2 4BF

Email:n.b.pitts@dundee.ac.uk

\section{Refereed Paper}

Received 20.08.03; Accepted 03.09.03

doi: 10.1038/sj.bdj.4810779

(๑) British Dental Journal 2003; 195: 631-635

The aims of this paper are to provide an impartial overview of the proposals and agenda for the future brought together in the NHS Dentistry: Options for Change document in the context of previous dental service delivery in primary care, and to start to explore what Options for Change could mean for the future of NHS dental services. Options has been described as perhaps the most radical and ground breaking opportunity for NHS dentistry to finally move forward after prolonged periods of stagnation and disharmony. The Options agenda has the potential to bring in a new style of NHS practice for dentistry, providing a way to finally get off the current 'treadmill' and to develop new NHS dental services where prevention is a priority and providing high quality dental treatment, tailored to the long term needs of the 21 st century patient, is the driving aim. However, the difficulties on all sides of leaving behind decades of disputes and overcoming real access, workforce and funding issues must not be underestimated or dismissed. The report was prepared by a working group comprising representatives from the profession, of patient groups and various sections of the Department of Health in England which was brought together by the then Chief Dental Officer. The key themes and priorities for action identified in Options include: local commissioning and funding, methods of remuneration for general dental practitioners, prevention and an oral health assessment for patients, clinical pathways, information and communication technology, practice structure, development of the dental team and the patient experience. The document also contains comprehensive reports of the three Options for Change task groups making recommendations for: 1) a new deal for patients national standards, 2) systems of delivery of dental care and 3) education, training and development of the dental team. Ways forward for delivering improved, modern, effective, preventive, patient-centred dental care have been identified. This potential can, however, only be realised if viable and sustainable agreements can be achieved to operationalise the best choices.

providing a way to finally get off the current 'treadmill' and to develop new NHS dental services where prevention is a priority and providing high quality dental treatment, tailored to the long terms needs of the 21 st century patient, is the driving aim. However, the difficulties on all sides of leaving behind decades of disputes and overcoming real access, workforce and funding issues must not be underestimated or dismissed.

The aims of this paper are to provide an impartial overview of the proposals and agenda for the future brought together in the NHS Dentistry: Options for Change document in the context of previous dental service delivery in primary care, and to start to explore what Options for Change could mean for the future of NHS dental services.

\section{BACKGROUND AND CONTEXT}

For a long time dentists in primary care have been unhappy with the way the traditional NHS framework allowed them to practice. After working within a system which can leave dentists frustrated and disengaged and the patient dis-empowered and confused, many have felt that the traditional and overcomplex fee-for-item of service payment system was out of touch with today's dentistry and in need of a major overhaul. Options for Change not only opens the door to dentistry's modernisation, but also provides a strategy to bring dentistry back into the mainstream of the NHS.

Potential change is not, however, a new phenomenon in dentistry. Over the last 55 years the profession has experienced many shifts in NHS policy, organisation 
and methods of working. The key difference is that previous changes that have been implemented have been rather marginal modifications of the existing system, targeting only 'symptoms' of problems, rather than any radical updating or re-design. This is perhaps why analogies of many of the problem issues prevalent within dentistry 20 years ago are still with us today. Press cuttings from the time of the Schanschieff Report ${ }^{2}$ of 1985 do not look that dissimilar to those seen after the Audit Commission's Initial Report of 2002. ${ }^{3}$

Since its inception in 1948, NHS dentistry has never been without its challenges. Few will remember the 1949 imposed ceiling on earnings, or the following 25\% fee cut, yet these early NHS dentists adapted to this situation, working hard to became efficient independent contractors remunerated by item of service. Apart from the introduction and adjustment of patient charges, there was relatively little structural change in the general dental services arrangements until the advent of the so-called 'new contract' of 1990. Whilst this introduced a hybrid 'capitation' system for children and changed arrangements for adult registration and continuing care, the majority of care was still paid for via a myriad of individual items of service in courses of treatment. Difficulties and disputes over the introduction of the 1990 contract led to the 'clawback' of fees debate of 1992 and a prolonged state of tension between the profession and the Health Departments, which apparently accelerated an exodus of dentists from the NHS.

This shift towards an increasing provision of private dental care, combined with complex workforce changes, have led to the far-reaching access issues experienced by NHS patients in recent years. This in turn has had a knock-on effect with the salaried community dental service, who were now responsible for providing a safety net to the growing numbers of deregistered individuals in addition to their other important roles in caring for priority and special needs groups as well as in the delivery of health promotion and epidemiology.

The fundamental problems with the delivery of NHS dentistry have been highlighted since the early 1990s. The Bloomfield Report ${ }^{3}$ in 1993 specifically cited a number of weaknesses with the then current NHS system including that of "the incentives and effects of a system based on a fee-for-item of service approach'. Later that same year the Health Committee commented that 'the present system of remuneration for dentists seems to have an inherent leaning towards instability which threatens to undermine the commitment of dental practitioners to the NHS,' and that 'the productivity incentives in the current system exert pressure on the quality of care'.

There is now widespread agreement that the need to completely overhaul the current dental NHS system is well overdue. Yet the profession is understandably cautious and wants to ascertain both the risks as well as the benefits of any major change, particularly when for independent contractors such changes will affect the financial viability of their practices.

Recent constitutional changes with devolution in the UK have led to more distinctive differences emerging between NHS arrangements for dentistry in England, Wales, Scotland and Northern Ireland. At the same time systematic and sweeping modernisation of the wider NHS continues apace with an increased focus on patient needs and (in England) devolving of decision making powers and resources to front line staff at local level via primary care trusts (PCTs). If dentistry is to become a more integrated part of the core NHS, it needs to change to match the new structures of the modernised system. The Options for Change report provides a framework to facilitate this dental modernisation process.

\section{THE WORKING GROUP}

The report was prepared by an Options for Change working group set up in 2001. This comprised representatives from the profession, of patient groups and various sections of the Department of Health in England which was brought together as individuals by the then Chief Dental Officer, Dame Margaret Seward.

The membership of the group is listed in full in the document, but it is noteworthy that a very broad range of expertise was harnessed across the 28 members. The dental members ranged from individuals from the BDA (Chief Executive, Chairman of the Executive Board, Chairman and Vice-Chairman of the General Dental Services Committee and Chair of the Central Committee for Community and Public Health Dentistry), to the Dean of the Faculty of Dental Surgery, Royal College of Surgeons of England, the Chief Executive of the General Dental Practitioners Association, the Chief Dental Officer of Denplan, a Dean from a Dental School and a Head of dental nurse training from another. Other members were drawn from the Consumers Association and the National Association for Citizens Advice Bureau. The members from the NHS came from across a wide range including a PCT Chief Executive and members from the NHS Modernisation Agency and the NHS Con- federation The secretariat of 11 was contributed by both the Department of Health and the BDA.

The Options for Change working group drew on a range of earlier documents and the report of the 2001 House of Lords Select Committee. ${ }^{5}$ The group were also informed by a dedicated workshop held in June 2001 between the Department of Health and the BDA.

Three task groups were set up within the working group. These were to focus on 1) a new deal for patients - national standards, 2) systems of delivery of dental care and 3) education, training and development of the dental team. These groups were chaired by Dr Roger Matthews, Dr Barry Cockcroft and Professor Anthony Blinkhorn respectively and also included a still broader representation from relevant areas.

\section{A VISION OF NHS DENTISTRY IN THE FUTURE}

Chapter 1 - A modernised service for patients in the 21st Century, sets out a vision of NHS dentistry in the future which is quite radical. It charts a framework for a new NHS dental service for England, delivered by primary care trusts. The service will be shaped by the needs of patients in the 21st century for high quality dental services which are responsive to local needs and allow, 'for the first time', the dental team to focus on preventive measures to combat dental disease and health inequalities, particularly in children. The report proposes that its recommendations are first tested and evaluated in demonstration sites by dentists and PCTs using personal dental services flexibilities.

Important elements of the vision include: 'Under the new proposals NHS treatment options to maintain dental health would be evidence based and regulated by service agreements with the dental profession'.

'NHS patient charges, currently numbering over 300 items, would be simplified'.

'In the proposed new NHS dental service, dentists would often offer both NHS and private dental care'.

'The choices for patients should be much more transparent that at present'. 'The new dental service would involve all members of the team, which would allow new roles and responsibilities to emerge'.

Illustrations are given of what the new service might look like.

The vision of modernisation encapsulated within the document has huge implications for rapid and positive change across many elements of dentistry. It would affect how dentists are remunerated, how patients are informed and how evidencebased dentistry and clinical governance are 
absorbed into routine practice; how information technology is woven into the fabric of NHS care and finally how education and training are perceived by dentist and patient alike. It will be important to ensure that such a range of new systems can evolve in the light of experiences in implementation at different geographical locations with a range of levels of oral health. There will also be a need to ensure that emerging new evidence, once evaluated, can readily be incorporated into the new NHS dental systems so that the care delivered can be shown to be both clinically and cost effective.

\section{KEY THEMES AND ISSUES, PRIORITIES FOR ACTION}

Chapter 2 identifies key themes and priorities for action and sets out eight critical facets of the Options agenda in terms of:

- Local commissioning and funding;

- Methods of remuneration for general dental practitioners;

- Prevention and an oral health assessment for patients;

- Clinical Pathways;

- Information and communication technology;

- Practice structure;

- Development of the dental team and

- Patient experience

This represents a major departure from previous NHS dental delivery systems and the text makes clear the interdependent linkages between many of the topics. To briefly consider each of these areas in turn:

\section{Local commissioning and funding}

'Primary care trusts should commission such services as are necessary to secure access to a high quality NHS dental service and to improve oral health and address inequalities. Funding will need to be devolved to a local level, with accompanying safeguards to protect provision for independent contractors and the salaried service, if necessary'.

This area is currently the subject of much discussion as PCTs become more firmly established and legislation makes provision for their new dental responsibilities. As the focus of all local NHS activity will be the PCT, it is important that any new NHS dental services can work smoothly with these new structures and organisations.

\section{Methods of remuneration for general dental practitioners \\ 'A menu of ways of paying dentists should be tested, including salary, capitation and simplified, modernised fee scale options. The possibility of a basic practice allowance}

should also be considered. There should be no sudden change but models should be tried out in demonstration sites and, if successful, made available across the service, building on experience of personal dental service pilots. There is unlikely to be one method which will fit all circumstances'.

Obviously this element represents an important change in the way NHS dentistry could be delivered. A key area which should facilitate beneficial change is the recognition (see under Clinical pathways below) that the payment of dentists should not be directly linked to the particular treatment choices offered to patients. The focus on quality, thorough diagnosis, prevention, the long term view of oral health and shared decision making with patients should remove perverse incentives. The recognition that one method alone is unlikely to suit all circumstances seems both helpful and realistic.

\section{Prevention and an oral health assessment for patients}

'A central recommendation is for the patient gateway to NHS dentistry to be through the oral health assessment. Unlike the present GDS examination the assessment should focus on the prevention of disease, lifestyle advice, the discussion of any necessary treatment options and the date of the next assessment'.

The standard oral health assessment, specifically tailored for 'children, workingage adults or older people' could ensure that there is a consistently firm diagnostic base to build appropriate treatment plans to offer to and discuss with patients. The provision of clear information in a standard format could do much to avoid the uncertainty and confusion for patients which has been associated with the current system. The choice of date between oral health reviews should be informed by the NICE guidance on recall intervals which should be available in 2004 .

\section{Clinical pathways}

'The direct association between payments to dentists and the types of treatment offered to patients needs to be removed where possible. Treatment should be offered to patients which is clinically appropriate, according to agreed protocols. A clinical pathway approach should be developed, based on best practice and the available evidence base.'

The explicit recognition of the need to determine clinical care which incorporates best practice (current consensus amongst clinicians and clinical experts) as well as the available evidence base (systematic syntheses of high quality research evidence which is directly applicable to the clinical question at issue) is a very important step forward for dental care. This approach (and the use of clinical care pathways) is entirely consistent with developments in other areas of the NHS, but represents a step forward for evidence based dentistry. The implicit recognition that there are significant gaps in the dental evidence base is also important and should drive the future research agenda towards areas relevant to primary dental care.

\section{Information and communication technology}

'Better use of information and communication technology (ICT) will assist the clinical pathways approach, as well as improving information for patients and encouraging better quality through clinical governance. Building an effective information infrastructure for dentistry is also essential for better integration with the rest of the NHS'.

The developing dental IT strategy should be able to deliver the information infrastructure required to make best use of the new approach to evidence based care. Ready access to previous dental and other health records, for example, should help the dental team deliver higher standards of care while access to the NHS net and clinical decision support has the potential to provide leading edge care under the NHS. All of these improvements are, however, contingent upon obtaining suitable agreements and resources.

\section{Practice structure}

'In the future there should be larger practices, using the skills of a range of staff including professionals complementary to dentistry and those dentists with specialist skills. The disincentives to such growth in the present system must be removed, through capital support, possibly through NHS Local Improvement Finance Trusts (NHS LIFT). A range of models is likely to be necessary and further work should be carried out on the optimal sizes and configurations of practices to balance easy access with cost effectiveness'.

The models envisaged here are in accord with developments in the rest of the NHS and should provide patients with a comprehensive range of services locally. They should also offer the dental team advantages, including a larger critical mass of staff, enhanced opportunities for training, clinical governance development and cover.

\section{Development of the dental team}

'The report includes ways in which the education, training and development of all members of the dental team can be improved to help the quality of patient care and enhance job satisfaction for everyone'. 
(These proposals will have to be developed further with the broad and shifting range of authorities, institutions and organisations involved).

This is a key area which has been held back for some time. The opportunity to develop the dental team in primary care under these arrangements holds out the prospect of being able to minimise some of the workforce related difficulties currently being experienced. However, there are a range of uncertainties to be addressed in this area, including the training, recruitment and retention of different types of team members in different parts of the country.

\section{Patient experience}

'Depending upon the outcome of testing, a new deal for patients with national standards is proposed. Priorities would be access to care, providing a quality service, better information for patients and oral health promotion'. An important premise throughout Options is that dentistry should be an integral part of the NHS and delivered in similar ways. In order to describe how the service might look, a scenario for a key element, the oral health assessment is outlined in the document. 'It would be a PCT's duty in the future to ensure that patients can access NHS dentistry in ways which meet local need.'

The development of a more patientcentred approach is a recurring theme across the Options document and this is consistent with moves in the wider NHS. Obviously access is a key issue, but crucially the document also sets out a series of ways which should improve clarity, choice and the quality of the patient experience, once they are receiving care within the new NHS dental service.

In terms of the current priorities for NHS dentistry in England and delivering the Options for Change agenda, there are a number of areas listed in the document as needing to be taken forward. These include PCT commissioning of dental services, remuneration systems which concentrate on quality, the development of clinical pathways, workforce issues, developing Dental ICT, mixing NHS and private dental care and developing new approaches to patient charges. Significant progress on a number of these issues has been made since the report was published last year.

Key elements of the new ways of working outlined above are to be tried out in primary care demonstration (field) sites, this process is currently underway. Across the sites selected from those declaring an interest, there will be tests of the broad range of the Options proposals.

\section{REPORTS OF THE TASK GROUPS}

The Options for Change document includes the comprehensive final reports from the three Options task groups. Each group has made important suggestions which should be debated and taken forward in the specific areas of patient centred services, delivery of dental services and education, training and the dental team.

\section{A new deal for patients - national standards}

Chapter 3 sets out the report of task group 1: A new deal for patients- national standards.

"Terms of reference: to develop possible standards for NHS patients to meet the needs and wishes of patients"

The main conclusions were:

That standards were identified 'which would provide the basis for an NHS dental service committed to providing patients with access, a quality service and full clear information. The standards also aimed to create a service focused upon oral health promotion and the prevention of disease, underpinned by cohesive support from the dental team and a modernised infrastructure'.

'A key theme of these standards is that of an increased priority to NHS dentistry at both a national and local level. Primary care trusts should be mandated to maintain an interest in the provision of dentistry to their communities through annually drawing up dental action plans. The standards also provide for dentistry to be included in healthy lifestyles programmes and the health improvement and modernisation programme. The group thought that that the Department of Health and primary care trusts should be mandated to achieve and maintain certain oral health standards among the population:

Other innovative suggestions were made which included: 'monitoring of oral health and population trends as an aid to planning workforce levels', 'all dentists to undergo customer service training to allow them to better empathise with patients', as well as an expansion in dentistry's role to cover participation in smoking cessation programmes and blood pressure checks.

This group reviewed a great deal of material bringing together the variety of uncoordinated standards and guidelines currently available. They also outlined a number of different scenarios to illustrate how the new approach would work and were clear about the need to move to a more patient-centred approach. They advocate the use of local and national standards to concentrate efforts towards the delivery of a patient-centred and effective service for the promotion of optimal oral health.

\section{Systems of delivery of dental care}

Chapter 4 sets out the report of task group 2: systems of delivery of dental care.

'Terms of reference: to propose a range of models for local delivery of NHS dentistry including possible changes to the remuneration system.

The main conclusions were:

'In order to create a system of NHS dentistry focused upon health outcomes rather than technical volume it is essential that the remuneration system separate income from treatment. No one system of remuneration suits everybody, practices and patients are different and there must be some accommodation for this in any new system. The group advocates that in the next few years, primary care trusts (PCTs) offer a menu of arrangements to dentists that might involve methods such as sessional payments, capitation, salaries or fee per item or often a combination of these'.

'Primary care dentistry as it currently exists (community dental services, personal dental services and general dental services) needs to be integrated. It is the the view of the group that in this way PCTs will find it easier to provide a dental service that is properly responsive to the changing needs of local communities.

'NHS Dentistry needs to be fully integrated with the rest of NHS primary care provision. One way to achieve this would be to initiate multi-surgery health centres in some geographical areas from which dental, medical and pharmacy services could be provided for the locality. In order to underpin the integration of dentistry with the rest of the NHS substantial capital investment in IT for dental practices would be required'

The conclusions here are unambiguous in pointing up the need for more than one method of remuneration and for a focus on rewarding health outcomes and not just the sheer volume of interventions delivered. The need for integration of dental services is logical and sensible, but care will be needed to bring together previously diverse (and in some cases competitive) groups under management arrangements new to general dentistry. The specific identification of modern IT infrastructure in dentistry as a barrier to integration with the wider (and more IT focused) NHS is a key point.

\section{Education, training and development of the dental team}

Chapter 5 sets out the report of task group 3: education, training and development of the dental team.

'Terms of reference: to develop proposals for the education, training and development of the whole dental team'

The main conclusions were: 
'Training should be directed towards the dental team as a whole, and particular efforts should be made to ensure that curriculum planning across the dental team recognises the complementary contributions of the different members of the team. The majority of dental treatment is undertaken in primary care so it is important to include this setting within the educational experience of the whole team in order to ensure that priority is given to the development of relevant practical and communication skills'.

'With the suggestion to increase the number of specialist dental practitioners in the primary care sector, patients will be able to access specialist services more readily in their own locality. Such a change in the skill mix in general dental practice would inevitably lead to changes in the undergraduate dental degree programme and would also impact on the training needs of professions complementary to dentistry'.

'Continuing professional development needs a new approach, with a proper appreciation of which skills are most useful to each individual to best meet patient need in the area where they practice. Clinical audit could highlight particular areas for development that would be of benefit to patients. In order to ensure that CPD could be readily available, inter-active computer based training should be introduced, subject to the necessary investment'

This Group's role is of pivotal significance as staff are the key, if improved dental services are to be achieved and maintained. Relevant clinical and communication skills and effective team dynamics will be of great importance if patients are to receive seamless, appropriate, high-quality care. The need for coordination of the curricula for team members may seem self-evident, but it is rarely achieved and is particularly important if changes in skill mix and team roles are to be introduced. Once again the potential of IT is highlighted, but so is the investment required to use inter-active computer based training.

\section{FUTURE OF NHS DENTAL PRIMARY CARE SERVICES?}

The innovative and hard teamwork which has resulted in the Options for Change framework and document, combined with subsequent developments such as the publication of the NHS Dental IT Strategy ${ }^{6}$ and legislative progress in the arrangements underpinning local commissioning of NHS services by primary care trusts, ${ }^{7}$ now provide an important and very unusual opportunity for NHS dentistry. Ways forward for delivering improved, modern, effective, preventive, patient-centred dental care have been identified and agreed in outline with the NHS by a range of dental and patient representatives. This potential can, however, only be realised if viable and sustainable agreements can be achieved to operationalise the best choices while addressing related funding and workforce issues. It is to be hoped that a repeat of the extended impasse seen over past decades can be avoided, so that real progress can now be made.

The views expressed above are those of the author in an individual capacity, they do not necessarily represent the views of any UK Health Department, the Chief Scientist Office of the Scottish Executive Department of Health, or the Medical Research Council's Health Services Research Collaboration. The author is indebted to Ms Jenny Hally (Clinical Research Fellow at DHSRU) for assistance in preparing background material for this paper.

1. NHS Dentistry: Options for Change. London: Department of Health, 2002 www.doh.gov.uk/cdo/optionsforchange

2. Report of the committee of enquiry into unnecessary dental treatment. (SchanschieffReport). London: HMSO, 1986.

3. Primary dental care services in England and Wales. Wales: Audit Commission Publications, 2002

4. Fundamental review of dental remuneration (Bloomfield report). London: HMSO, 1992.

5. Report of the 2001 House of Lords Select Committee Spring 2001.

6. An information technologystrategy for NHS dentistry in the 21st century. October 2002

7. Health and Social Care (Community Health and Standards) Bill. Bill 70. London: House of Commons, March 2003 